
\title{
28 Research Suare \\ Identification of the Role of SOX2 During Early Embryogenesis in Pigs
}

\section{Mingyun Lee}

Seoul National University College of Agriculture and Life Sciences

\section{Jong-Nam Oh}

Seoul National University College of Agriculture and Life Sciences

\section{Seung-Hun Kim}

Seoul National University College of Agriculture and Life Sciences

\section{Kwang-Hwan Choi}

Seoul National University College of Agriculture and Life Sciences

\section{Dong-Kyung Lee}

Seoul National University College of Agriculture and Life Sciences

\section{Gyung Cheol Choe}

Seoul National University College of Agriculture and Life Sciences

Jinsol Jeong

Seoul National University College of Agriculture and Life Sciences

Chang-Kyu Lee ( $D$ leeck@snu.ac.kr)

Agriculture and life science, Seoul National University https://orcid.org/0000-0001-6341-0013

\section{Research}

Keywords: Lineage specification, SOX2, preimplantation embryo, pig, CRISPR Cas9, microinjection

Posted Date: November 12th, 2020

DOl: https://doi.org/10.21203/rs.3.rs-104075/v1

License: (c) (1) This work is licensed under a Creative Commons Attribution 4.0 International License. Read Full License 


\section{Abstract}

\section{Background}

The lineage specification of mammalian embryos during preimplantation development has been studied for a long time but is still unclear. To understand the developmental process, many studies have examined lineage markers and mechanisms focusing on mouse embryos, but there are differences from human embryos. Pigs have been studied extensively in the field of disease model animals and xenotransplantation because of their physiological similarity with humans. Therefore, it is necessary to analyze gene expression patterns and lineage specification markers during early embryogenesis in pigs, a model animal similar to humans.

Results

Analysis of the expression pattern of the core pluripotent factors (OCT4, SOX2 and NANOG) of preimplantation porcine embryos showed that $S O X 2$ was only expressed in some cells from the early stage, so SOX2 was selected as an ICM inducible factor candidate. Next, transcript and protein expression patterns were estimated at the early stage (Day 5) and late stage (Day 7) of blastocysts injected with the CRISPR Cas9 system selected through gRNA validation. An ICC assay revealed that the expression of ICM-related genes (SOX2, NANOG and SOX17), except OCT4, was suppressed, and the total cell number was also decreased. Likewise, according to real-time PCR analysis, pluripotency-related genes (NANOG, SOX17 and SMAD7), excluding OCT4, and proliferation-related genes (KDM8 and DDB1) were decreased in SOX2-targeted blastocysts, which showed more differences in late-stage blastocyst than in early-stage blastocyst. Last, in SOX2-overexpressing embryos, the total blastocyst cell number was greatly increased, but the ICM/TE ratio decreased.

\section{Conclusions}

Taken together, our results demonstrated SOX2 is essential for ICM formation and cell proliferation in porcine early stage embryogenesis. These findings will help to elucidate gene regulation related to lineage specification during porcine early development.

\section{Methods}

The care and experimental use of pigs and mice were approved by the Institute of Laboratory Animal Resources, Seoul National University (SNU-140328-2). Unless otherwise stated, all chemicals were obtained from Sigma-Aldrich Corp. (St. Louis, MO, USA).

\section{In vitro embryo production}

The ovaries of the prepubertal gilts were obtained from a local slaughterhouse (Anyang-si, Gyeonggi-do, Korea) and transferred to the laboratory in warm saline. Cumulus-oocyte complexes (COCs) were collected by aspirating 3- to 7-mm follicles of the prepubertal gilts with a 10-mL syringe and an 18-gauge 
needle. Sediments were washed with TL-HEPES-PVA medium, and oocytes with compact cumulus cells and granulated cytoplasm were selected for in vitro maturation. The washed COCs were cultured in tissue culture medium (TCM-199; Life Technologies, Carlsbad, CA, USA) containing $10 \mathrm{ng} / \mathrm{mL}$ epidermal growth factor, $1 \mathrm{mg} / \mathrm{mL}$ insulin, and $10 \%$ porcine follicular fluid for 44 hours at $39^{\circ} \mathrm{C}$ at $5 \% \mathrm{CO} 2$ and $100 \%$ humidity. The COCs were matured with $10 \mathrm{IU} / \mathrm{mL}$ gonadotropin hormone, pregnant mare serum gonadotropin (Lee Biosolutions, Maryland Heights, MO, USA), and human chorionic gonadotropin for the first 22 hours. The COCs were then matured under hormone-free conditions. To generate parthenotes, cumulus-free oocytes were activated with an electric pulse $(1.0 \mathrm{kV} / \mathrm{cm}$ for $60 \mathrm{~ms})$ in activation medium (280 mM mannitol, $0.01 \mathrm{mM} \mathrm{CaCl} 2,0.05 \mathrm{mM} \mathrm{MgCl}$ ) ) using a BTX Electrocell Manipulator (BTX, CA, USA), followed by 4 hours of incubation in PZM3 medium containing $2 \mathrm{mmol} / \mathrm{L}$ 6-dimethylaminopurine.

\section{Cytoplasmic injection of the DNA-lipofectamine complex}

For the microinjection assay, $10 \mu \mathrm{l}$ of $90 \mathrm{ng} / \mu \mathrm{l}$ of DNA in combination with $1 \mu \mathrm{l}$ of Lipofectamine (Stem reagent; Thermo Fisher Scientific) was incubated for $5 \mathrm{~min}$ in Media-199 (Gibco), and the final DNA concentration was $15 \mathrm{ng} / \mu \mathrm{l}$. One day after PA, the embryos at the 2-cell stage were injected with $2 \mathrm{pl}$ of plasmid-lipofectamine solution in manipulation media. The microinjection procedure was conducted with a micromanipulator (Eclipse TE2000, Nikon, Tokyo, Japan) with holding and injection pipettes. We used a Femtotip $\otimes$ (Eppendorf, Hamburg, Germany) as an injection pipette.

\section{Immunocytochemistry}

Each stage of embryos without zona pellucida was fixed in 4\% paraformaldehyde for 15 min at room temperature. Fixed samples were permeabilized using 1\% Triton X-100 for 1 hour at room temperature and washed three times with phosphate-buffered saline (PBS). The embryos were blocked using $10 \%$ goat serum or donkey serum in PBS for 1 hour at room temperature. Samples were stained with antiSOX2 $(5 \mu \mathrm{g} / \mathrm{ml})$, NANOG $(1 \mu \mathrm{g} / \mathrm{ml})$, OCT4 $(1 \mu \mathrm{g} / \mathrm{ml})$, and SOX17 $(1 \mu \mathrm{g} / \mathrm{ml})$ in PBS containing $10 \%$ donkey serum at $4^{\circ} \mathrm{C}$ overnight. After washing 3 times in washing solution (PBS with $0.2 \%$ Tween-20 and $1 \%$ BSA for $10 \mathrm{~min}$ ), embryos were incubated with donkey anti-rabbit Alexa594 (Invitrogen, Carlsbad, California, USA) in PBS with $10 \%$ donkey serum at RT for 1 hour. All samples were washed 3 times with washing solution after secondary antibody treatment. Immunostained embryos were mounted on a slide glass with Prolong gold with DAPI (Invitrogen) and cured for more than 24 hours. We described the list of antibodies in Table S2. The imaging tool of the micromanipulator was used to take fluorescence images. We used the ImageJ program to obtain images.

\section{Quantitative RT-PCR}

Pooled embryos at each stage of in vitro-produced embryos (2-3-cell, n=20; 4-cell, $n=20 ; 6-8$-cell, $n=20$; morula, $n=10$; and $B L, n=5$ ) were processed with an Arcturus ${ }^{\circledR}$ PicoPure ${ }^{\circledR}$ RNA Isolation Kit (Applied Biosystems, Foster City, California, USA) following the manufacturer's instructions. cDNA was synthesized using a High-Capacity RNA-to-cDNA Kit (Applied Biosystems, USA). Extracted cDNA samples 
were amplified using Power SYBR Green Master Mix (Applied Biosystems, USA) containing 1 pmol of each primer set listed in Table S1 in a $10 \mu \mathrm{l}$ reaction volume. Amplification and detection were conducted using the ABI 7300 Real-Time PCR System (Applied Biosystems, USA) under the following conditions: one cycle of $50^{\circ} \mathrm{C}$ for $2 \mathrm{~min}$ and $95^{\circ} \mathrm{C}$ for $10 \mathrm{~min}$, followed by 40 cycles of denaturation at $95^{\circ} \mathrm{C}$ for $15 \mathrm{~s}$ and annealing/extension for $1 \mathrm{~min}$ (annealing/extension temperatures dependent on each primer set). The dissociation curves were analyzed, and the amplified products were loaded onto gels to confirm the specificity of the PCR products. The relative expression level was calculated by normalizing the threshold cycle $(\mathrm{Ct})$ values of each gene to that of the reference gene beta-actin (ACTB) via the delta-delta $\mathrm{Ct}$ method.

\section{Production of CRISPR Cas9 Vectors and SOX2 Gene Expression Vector}

The selected guide sequence was inserted into the pX330 and pX458 vectors. The CRISPR-target site is depicted in Figure 2. The porcine SOX2 coding region sequence was synthesized and replaced in the human SOX2 site of the pCXLE-hS + Egfp vector, Addgene \#74945. All vectors were verified by nucleotide sequencing.

\section{Culture of porcine embryonic fibroblasts and plasmid transfection}

Basic cell culture and lipofection were carried out following procedures in our previous report (1). Briefly, pEF cells were plated in 6-well plates and transfected with $300 \mathrm{ng}$ of pX330 constructs and $300 \mathrm{ng}$ of pCAG-EGxxFP constructs using Lipofectamine 3000 Reagent (Thermo Fisher Scientific, Waltham, MA, USA). We replaced culture media with fresh modified Dulbecco's modified Eagle's medium (DMEM) 24 hours after lipofection, followed by 2 days of culture. For genotyping of transfected pEF, genomic DNA was extracted from pEF using the G-spin Total DNA Extraction Kit (iNtRON Biotechnology, Korea). Genomic DNA samples were amplified using 10 pmol of porcine SOX2-specific primers and 2 X PCR master mix solution (iNtRON Biotechnology).

\section{Statistical analysis}

Statistical analysis of data was performed using GraphPad Prism Software (version 5.01; San Diego, CA, USA). Significant differences among experimental groups were determined by one-way analysis of variance followed by Tukey's multiple comparison test. A p-value $<0.05$ was considered significant. Data are presented as the mean \pm standard error.

\section{Background}

In mammals, two lineage segregations occur during preimplantation development. First, the cell population is divided into the inner cell mass (ICM) and trophectoderm (TE), and second, the ICM is divided into the epiblast (EPI) and primitive endoderm (PrE). Many studies have revealed that this process is controlled by complex genomics and molecular networks in mammals. In mice, Oct4 is known to be the gene that drives this first lineage segregation with $\mathrm{Cdx} 2$ (2). However, recent studies highlight the 
importance of SOX2 as a gene that induces derivation with $\operatorname{ICM}(3,4)$. SOX2, along with OCT4 and NANOG, is one of the core transcription factors and is specifically expressed in the ICM in mammalian embryos $(5,6)$. In addition, SOX2 is also expressed in embryonic stem (ES) cells and germ cells, so it is considered a key transcription factor for pluripotency (7-9). For these reasons, SOX2 is used for reprogramming somatic cells into induced pluripotent stem (iPS) cells $(10,11)$. In particular, SOX2 is a faithful marker of pluripotency among several pluripotent genes in porcine preimplantation embryos (6). In contrast, OCT 4 is expressed in both ICM and TE, and it is coexpressed with the TE marker CDX2 from the D5 blastocyst stage and is essential for TE formation in pigs. In the human blastocyst, OCT4 is also expressed in TE, so it is more similar to embryos in pigs, which make them a better model animal than mice $(12,13)$. Due to this similarity with humans, pigs are being studied as a model animal in early development (14-16).

Transgenic mammalian embryo studies continue to advance. The CRISPR (clustered regularly interspaced, short palindromic repeat) cas9 (CRISPR-associated) system, which has been studied extensively in recent years, has improved efficiency and is being used for genetic modification research. CRISPR-Cas9 was used to clarify the role of genes during preimplantation development. A recent study revealed that OCT4/Oct4 has different functions in human and mouse embryogenesis (17). In bovine embryos, it was found that OCT4 is required for NNAOG expression by OCT4 disruption (18). NANOG is essential for epiblast formation and maintenance of pluripotency using NANOG-targeted bovine embryos (19). Alternatively, lineage specification in mammalian embryos is being studied through overexpression analysis. The role of OCT4 and NANOG in embryos was analyzed by somatic cell nuclear transfer (SCNT) of stably overexpressed cell lines to embryos $(20,21)$. Recently, RNA direct cytoplasmic injection was performed for overexpression to control embryonic cell fate $(4,22)$. Although many studies have analyzed the function of several genes during early embryo development, the role of SOX2 is still not defined.

In this study, we investigated the expression patterns of core transcription factors and the role of SOX2 in parthenogenetically activated (PA) porcine embryos. First, we investigated gene expression patterns at each stage during early embryogenesis to select an ICM-faithful marker. Then, we injected CRISPR/Cas 9 vectors into a 2-cell stage embryo to knock out the SOX2 gene. After the culture period, the transcript and protein expression patterns of the control blastocyst and SOX2-targeted blastocyst were analyzed by immunostaining and qPCR in early and late blastocyst stages. Next, we induced overexpression by microinjecting exogenous SOX 2 into the embryos, and morphological differences and gene expression patterns were evaluated at the blastocyst stage. This approach revealed the role of SOX2 in the development of preimplantation embryos and will aid in understanding the mechanism of lineage segregation.

\section{Results}

\section{Pluripotent gene expression patterns in preimplantation embryos}


To identify the gene expression patterns of OCT4, SOX2, and NANOG in early porcine embryos, a quantitative PCR (qPCR) assay was performed in porcine preimplantation embryos derived from parthenogenesis (Figure 1A and 1B). The expression of all pluripotent genes was upregulated to the 6-8 cell stage and then decreased starting from the morula stage. Next, the expression of OCT4, SOX2, and NANOG was examined in porcine morula and early (D5) and late (D7) blastocysts through immunocytochemistry (ICC) assays. SOX2 protein was only located in some cells in the morula and in the ICM from D5 and D7 blastocysts but not TE cells. NANOG protein was not found in the morula stage but was expressed in the ICM from D5 blastocysts. OCT4 was expressed in all cells in the morula and D5 blastocysts, but some D7 blastocysts expressed OCT4 in both the ICM and TE, while others were expressed only in the ICM. Therefore, we hypothesized that SOX2 is an ICM formation marker during porcine embryogenesis.

\section{Construction and validation of the CRISPR/Cas9 and gRNA expression vectors for SOX2knockout}

To select the targeting site of the SOX2 gene, we used the CRISPR gRNA design tool (https://chopchop.cbu.uib.no) to improve efficiency and minimize off-targeting effects. Three candidate target sites were selected (Figure 2B), and the pCAG-EGxxFP reporter system was used to evaluate them (23). The SOX2 target sequences were cloned into the pX330 plasmid, and the SOX2 sequences (1-450 bp) were cloned into the PCAG-EGxxFP plasmid. When gene-targeted cleavage was induced, the reporter system expressed EGFP reconstituted by homology-dependent repair (HDR). We first cotransfected pX330-SOX2 gRNA and pCAG-EG(SOX2)FP into porcine embryonic fibroblasts, and EGFP was observed 48 hours later. The negative control did not express GFP, and the gRNA targeting gRNA-2 (targeting 72 bp) showed the highest activity (Figure $2 \mathrm{C}$ ). To determine whether gRNA-2 induces indels in the target sequence, the gDNA sequence of PEF transfected with pX330-SOX2 gRNA was analyzed. When SOX2 of the extracted gDNA was amplified through PCR and analyzed by Sanger sequencing, it was confirmed that a frameshift occurred in the transfected cell lines (Figure 2D). These results suggest that $p X 330$ SOX2-2 adequately induces DSBs in the targeted site of reporter plasmids in PEF cells.

\section{Effects of SOX2-targeting plasmid microinjection on embryo development}

To investigate whether SOX2 plays an important role in ICM formation in preimplantation porcine embryos, pX458+gRNA-2, which contains Cas9 and EGFP, was injected into 2-cell stage embryos. We used a DNA plasmid-liposome cytoplasmic microinjection system to establish SOX2-targeted embryos (24). The expression of EGFP contained in the plasmid confirmed that the plasmid operated normally (Figure 2E). The injected blastocyst had a small size, but the blastocoel was formed.

Immunofluorescence analysis revealed that most of the pX458-gRNA was injected into day 5 blastocysts, and SOX2 protein expression was downregulated (Figure 3A). Some embryos had no SOX2-positive cells, and the other embryos had fewer SOX2-positive cells compared to the uninjected group. Similarly, NANOG-positive cells were present less frequently in the injected blastocysts than in the control blastocysts. Likewise, in the late blastocyst stage, there were fewer SOX2-and NANOG-positive cells in blastocyst injected with pX458-gRNA, and SOX17, a primitive endoderm marker, was also expressed at 
lower levels (Figure 3B). In addition, the total cell number of blastocysts and SOX2-, NANOG-, and SOX17positive cells decreased in embryos injected with pX458-gRNA (Table 1). In contrast, OCT4 protein was expressed in most cells, such as control blastocysts, meaning that it was not significantly influenced by SOX2 knockout.

To identify the transcriptional consequences of SOX2 reduction, qPCR analysis was performed on noninjected and pX458-gRNA-injected BL. In early-stage BL, the expression levels of SOX2, OCT4, and NANOG were not significantly different according to SOX2 targeting (Figure 4A). The expression of SOX17 decreased, and the expression of SMAD7, which is known to be involved in ES cell self-renewal and iPSC reprogramming, also decreased (25). KDM8 is directly controlled by SOX2, which is known to regulate embryonic cell proliferation, and its expression is decreased in SOX2-targeted blastocyst (Figure 3C) (26, 27). Known to play an important role in embryo proliferation, $D D B 1$ tended to decrease in the SOX 2 target blastocysts (28). In the late blastocyst stage, the expression of genes excluding SOX2 and OCT4 decreased in the SOX2-targeted group compared to the control group (Figure 3C, 3D). These findings suggest that targeting SOX2 in porcine embryos reduces the expression of ICM-specific genes except OCT 4 and has a negative effect on cell proliferation.

\section{Overexpression of exogenous SOX2 through microinjection assay}

Next, we evaluated the functional effects of transient overexpression of SOX2 in porcine embryos. DNA plasmid-liposome cytoplasmic microinjection was implemented in 1-cell stage embryos and 2-cell stage embryos. The embryo injected in the 1-cell stage expressed EGFP overall, and the embryo injected into the 2-cell stage expressed a mosaic pattern. Most of the 1-cell stage SOX2-overexpressing embryos were arrested at the morula stage or early D5 blastocyst stage and did not form a normal blastocoel (Figure 5A). On the other hand, CMV-GFP plasmid-injected embryos and media (TCM-199)-injected embryos developed into blastocysts (Table 2). The 2-cell stage injected embryos developed to day 7 blastocysts and hatched from the zona pellucida. The ICC assay showed that outliers occurred in the total cell number of SOX2-overexpressing embryos (Figure 5B). Blastocysts with more than 250 cell counts were formed, but the SOX2-positive cell ratio decreased (Figure 5C, 5D). In the qPCR assay, the expression of SOX2 and NANOG increased compared to the control, but OCT4 showed no significant difference (Figure $5 \mathrm{E})$. These results indicate that SOX2 is related to proliferation and to other pluripotent genes in porcine embryos.

\section{Discussion}

The role of SOX2 in preimplantation embryos has been studied in mice, but it differs from species to species and needs to be studied in pigs. Mouse embryos with disruption of Sox 2 achieved blastocyst formation but failed to develop (29). However, murine 1-cell stage and 2-cell stage embryos overexpressing Sox 2 arrest before the morula stage (30). These findings have been described in mice but not in pigs, so it was necessary to study the role of SOX2 during embryogenesis. In our study, SOX2targeted embryos formed blastocoels but failed to form ICM, resulting in consistent outcomes with 
mouse embryos. Conversely, SOX2-overexpressing 2-cell stage asymmetric embryos could develop into blastocysts. Because there is a difference in the gene expression system, the RNA-based system induces immediate expression, whereas the DNA-lipofectamine system is delayed by ZGA (zygotic genome activation). ZGA starts at the 4-cell stage in pigs, and previous research showed that gene expression occurs later in bovine embryos than murine embryos with microinjection of DNA plasmid $(31,32)$. As the expression of exogenous SOX2 was delayed by ZGA, it did not affect early embryonic gene expression. Therefore, SOX2-overexpressing embryos may appear to generally develop into blastocysts. The gene expression system can be used differently depending on the species, and the timing of exogenous gene expression can be controlled. Under other conditions, most embryos overexpressing SOX2 at the 1-cell stage were arrested at the morula stage without being divided into two lineages (Figure 5A). SOX2 in the porcine preimplantation embryo is specifically expressed in a few cells in the morula, ICM in the early stage blastocyst, and EPI in the spherical embryo (33). However, it seems that exogenous SOX2 injection at the 1-cell stage interferes with the distinct distribution of SOX2 at the morula stage and inhibits intact segregation. Another possibility is that a high level of SOX2 can lead to differentiation. This is in agreement with previous findings in which the overexpression of SOX2 in human ESCs induces trophectodermal differentiation. Similarly, overexpression of Sox2 in mouse ESCs downregulates Sox2 and Oct4 target genes $(34,35)$.

Interestingly, unlike NANOG, the mRNA expression of OCT4 and the protein expression of OCT4 were not influenced by overexpression or knockout of SOX2 in porcine embryos (Figure 3). Likewise, Carm 1-and LincGET-overexpressing mouse embryos show a significant change in the expression levels of Sox2 and Nanog but not Oct4 (4). Moreover, as a result of quantifying the binding of Oct4 and Sox2 to DNA in mouse embryos, Sox2 engages in more long-lived interactions than Oct4 at the 4-cell stage (3). In another study, OCT4/Oct4 knockout in mouse and human embryos decreased the expression of NANOG/Nanog (EPI marker) and SOX17/Sox17 (primitive endoderm marker) (17). Correspondingly, in OCT4 knockout bovine embryos, the expression of NANOG was suppressed, but the first lineage segregation was not affected (18). According to these studies, SOX2 and OCT4 are the genes that control blastocyst development and pluripotency. However, more studies are needed to determine their roles and interactions.

Furthermore, our data suggest that SOX2 is required for embryo proliferation (Table 1, Figure 5B). These results match those mentioned in studies of Sox2-targeted embryos in mice (29). Likewise, previous studies showed that overexpression of SOX2 enhances proliferation in human mesenchymal stem cells and Wharton's jelly stem cells $(36,37)$. Additionally, SOX2 is strictly required for proliferation in human MSCs and primordial germ cells $(7,38)$. In the above studies, overexpression of SOX2 triggers high expression of Cyclin D1, accelerating the $\mathrm{G} 1$ to $S$ transition. Based on these findings, we speculate that SOX2 promotes cell proliferation during embryo development as well as in pluripotent cells and multipotent stem cells. However, the association between SOX2 and proliferation in porcine embryos and ESCs is not yet clear. Since authentic porcine ESCs have been established in recent studies, it is expected that proliferation studies will be possible based on these results (39). 


\section{Conclusion}

In summary, we targeted or overexpressed SOX2 in porcine embryos, thus suggesting that SOX2 plays an important role in ICM formation and cell proliferation. We hope that this study will help to understand the roles and networks of genes in preimplantation embryos between species in the future.

\section{Abbreviations}

ICM: Inner cell mass

TE: Trophectoderm

Epi: Epiblast

PrE: Primitive endoderm

CRISPR: Clustered regularly interspaced, short palindromic repeat

Cas9: CRISPR-associated

ICC: Immunocytochemistry

ESC: Embryonic stem cells

iPSC: Induced pluripotent stem cells

COCs: Cumulus-oocyte complexes

PA: Parthenogentically activated

SCNT: Somatic cell nuclear transfer

EGFP: Enhanced green fluorescent protein

Pef: Porcine embryonic fibroblasts

RT-qPCR: Quantitative real-time PCR

gRNA: guide RNA

HDR: Homology dependent repair

ZGA: Zygotic genome activation

\section{Declarations}




\section{Ethics approval and consent to participate}

The authors assert that all procedures in this work complied with the ethical standards of the relevant national and institutional guides on the care and use of laboratory animals. The Institutional Animal Care and Use Committee, Seoul National University approved the care and experimental use of pigs (SNU181024-8).

\section{Consent for publication}

Not applicable.

\section{Availability of data and material}

All data generated or analyzed during this study are included in this published article. Competing interests The authors declare that they have no competing interests.

\section{Funding}

This work was supported by the BK21 Plus Program and the National Research Foundation of Korea (NRF) Grant funded by the Korea government (NRF-2019R1C1C1004514).

\section{Competing interests}

The authors declare that they have no competing interests.

\section{Authors' contributions}

M. Lee, J.-N. Oh, S.-H. Kim, K.-H. Choi, D.-K. Lee and C.-K. Lee designed research; M. Lee, J.-N. Oh, S.-H. Kim, GC. Choe and J. Jeong performed research; M. Lee, J.-N. Oh, S.-H. Kim, K.-H. Choi, D.-K. Lee analyzed data; M. Lee and C.-K. Lee wrote the paper; C.-K. Lee finally approved the manuscript.

\section{Acknowledgments}

Not applicable.

\section{References}

1. Oh J-n, Choi K-h, Lee C-k. Multi-resistance strategy for viral diseases and in vitro short hairpin RNA verification method in pigs. Asian-Australasian journal of animal sciences. 2018;31(4):489.

2. Wu G, Schöler HR. Role of Oct4 in the early embryo development. Cell Regeneration. 2014;3(1):1-10.

3. White MD, Angiolini JF, Alvarez YD, Kaur G, Zhao ZW, Mocskos E, et al. Long-lived binding of Sox2 to DNA predicts cell fate in the four-cell mouse embryo. Cell. 2016;165(1):75-87.

4. Wang J, Wang L, Feng G, Wang Y, Li Y, Li X, et al. Asymmetric expression of LincGET biases cell fate in two-cell mouse embryos. Cell. 2018;175(7):1887-901. e18.

5. Cauffman G, De Rycke M, Sermon K, Liebaers I, Van de Velde H. Markers that define stemness in ESC are unable to identify the totipotent cells in human preimplantation embryos. Human Reproduction. 2009;24(1):63-70. 
6. Liu S, Bou G, Sun R, Guo S, Xue B, Wei R, et al. Sox2 is the faithful marker for pluripotency in pig: evidence from embryonic studies. Developmental dynamics. 2015;244(4):619-27.

7. Campolo F, Gori M, Favaro R, Nicolis S, Pellegrini M, Botti F, et al. Essential role of Sox2 for the establishment and maintenance of the germ cell line. Stem cells. 2013;31(7):1408-21.

8. Masui S, Nakatake Y, Toyooka Y, Shimosato D, Yagi R, Takahashi K, et al. Pluripotency governed by Sox 2 via regulation of Oct3/4 expression in mouse embryonic stem cells. Nature cell biology. 2007;9(6):625-35.

9. Boyer LA, Lee TI, Cole MF, Johnstone SE, Levine SS, Zucker JP, et al. Core transcriptional regulatory circuitry in human embryonic stem cells. cell. 2005;122(6):947-56.

10. Takahashi K, Yamanaka S. Induction of pluripotent stem cells from mouse embryonic and adult fibroblast cultures by defined factors. cell. 2006;126(4):663-76.

11. Giorgetti A, Montserrat N, Aasen T, Gonzalez F, Rodríguez-Pizà I, Vassena R, et al. Generation of induced pluripotent stem cells from human cord blood using OCT4 and SOX2. Cell stem cell. 2009;5(4):353.

12. Iwasawa T, Takahashi K, Goto M, Anzai M, Shirasawa H, Sato W, et al. Human frozen-thawed blastocyst morphokinetics observed using time-lapse cinematography reflects the number of trophectoderm cells. PloS one. 2019;14(1):e0210992.

13. Strumpf D, Mao C-A, Yamanaka Y, Ralston A, Chawengsaksophak K, Beck F, et al. Cdx2 is required for correct cell fate specification and differentiation of trophectoderm in the mouse blastocyst. Development. 2005;132(9):2093-102.

14. Choi K-H, Lee C-K. Pig pluripotent stem cells as a candidate for biomedical application. J Anim Reprod Biotechnol. 2019;34(3):139-47.

15. Choi K-H, Lee D-K, Oh J-N, Kim S-H, Lee M, Jeong J, et al. Generation of Neural Progenitor Cells from Pig Embryonic Germ Cells. Journal of Animal Reproduction and Biotechnology. 2020;35(1):42-9.

16. Oh J-N, Lee M, Choe GC, Lee D-K, Choi K-H, Kim S-H, et al. Identification of the Lineage Markers and Inhibition of DAB2 in In Vitro Fertilized Porcine Embryos. International Journal of Molecular Sciences. 2020;21(19):7275.

17. Fogarty NM, McCarthy A, Snijders KE, Powell BE, Kubikova N, Blakeley P, et al. Genome editing reveals a role for OCT4 in human embryogenesis. Nature. 2017;550(7674):67-73.

18. Simmet K, Zakhartchenko V, Philippou-Massier J, Blum H, Klymiuk N, Wolf E. OCT4/POU5F1 is required for NANOG expression in bovine blastocysts. Proceedings of the National Academy of Sciences. 2018;115(11):2770-5.

19. Ortega MS, Kelleher AM, O'Neil E, Benne J, Cecil R, Spencer TE. NANOG is required to form the epiblast and maintain pluripotency in the bovine embryo. Molecular Reproduction and Development. 2020;87(1):152-60.

20. Zhang L, Luo YB, Bou G, Kong QR, Huan YJ, Zhu J, et al. Overexpression Nanog activates pluripotent genes in porcine fetal fibroblasts and nuclear transfer embryos. The Anatomical Record: Advances in Integrative Anatomy and Evolutionary Biology. 2011;294(11):1809-17. 
21. Kim SJ, Koo OJ, Park HJ, Moon JH, da Torre BR, Javaregowda PK, et al. Oct4 overexpression facilitates proliferation of porcine fibroblasts and development of cloned embryos. Zygote. 2015;23(5):704-11.

22. Bou G, Liu S, Sun M, Zhu J, Xue B, Guo J, et al. CDX2 is essential for cell proliferation and polarity in porcine blastocysts. Development. 2017;144(7):1296-306.

23. Mashiko D, Fujihara Y, Satouh Y, Miyata H, Isotani A, Ikawa M. Generation of mutant mice by pronuclear injection of circular plasmid expressing Cas9 and single guided RNA. Scientific reports. 2013;3:3355.

24. Vichera G, Moro L, Salamone D. Efficient transgene expression in IVF and parthenogenetic bovine embryos by intracytoplasmic injection of DNA-liposome complexes. Reproduction in domestic animals. 2011;46(2):214-20.

25. Yu Y, Gu S, Li W, Sun C, Chen F, Xiao M, et al. Smad7 enables STAT3 activation and promotes pluripotency independent of TGF- $\beta$ signaling. Proceedings of the National Academy of Sciences. 2017;114(38):10113-8.

26. Ishimura A, Minehata K-i, Terashima M, Kondoh G, Hara T, Suzuki T. Jmjd5, an H3K36me2 histone demethylase, modulates embryonic cell proliferation through the regulation of Cdkn1a expression. Development. 2012;139(4):749-59.

27. Hsia DA, Tepper CG, Pochampalli MR, Hsia EY, Izumiya C, Huerta SB, et al. KDM8, a H3K36me2 histone demethylase that acts in the cyclin A1 coding region to regulate cancer cell proliferation. Proceedings of the National Academy of Sciences. 2010;107(21):9671-6.

28. Cang Y, Zhang J, Nicholas SA, Bastien J, Li B, Zhou P, et al. Deletion of DDB1 in mouse brain and lens leads to p53-dependent elimination of proliferating cells. Cell. 2006;127(5):929-40.

29. Avilion AA, Nicolis SK, Pevny LH, Perez L, Vivian N, Lovell-Badge R. Multipotent cell lineages in early mouse development depend on SOX2 function. Genes \& development. 2003;17(1):126-40.

30. Pan H, Schultz RM. Sox2 modulates reprogramming of gene expression in two-cell mouse embryos. Biology of reproduction. 2011;85(2):409-16.

31. Arrell V, Day B, Prather R. The transition from maternal to zygotic control of development occurs during the 4-cell stage in the domestic pig, Sus scrofa: quantitative and qualitative aspects of protein synthesis. Biology of Reproduction. 1991;44(1):62-8.

32. Iqbal K, Barg-Kues B, Broll S, Bode J, Niemann H, Kues WA. Cytoplasmic injection of circular plasmids allows targeted expression in mammalian embryos. Biotechniques. 2009;47(5):959-68.

33. Ramos-lbeas P, Sang F, Zhu Q, Tang WW, Withey S, Klisch D, et al. Pluripotency and X chromosome dynamics revealed in pig pre-gastrulating embryos by single cell analysis. Nature communications. 2019;10(1):1-17.

34. Adachi K, Suemori H, Yasuda Sy, Nakatsuji N, Kawase E. Role of SOX2 in maintaining pluripotency of human embryonic stem cells. Genes to cells. 2010;15(5):455-70.

35. Kopp JL, Ormsbee BD, Desler M, Rizzino A. Small increases in the level of Sox2 trigger the differentiation of mouse embryonic stem cells. Stem cells. 2008;26(4):903-11. 
36. Han S-M, Han S-H, Coh Y-R, Jang G, Ra JC, Kang S-K, et al. Enhanced proliferation and differentiation of Oct4-and Sox2-overexpressing human adipose tissue mesenchymal stem cells. Experimental \& molecular medicine. 2014;46(6):e101-e.

37. Świstowska M, Gil-Kulik P, Krzyżanowski A, Bielecki T, Czop M, Kwaśniewska A, et al. Potential effect of SOX2 on the cell cycle of Wharton's jelly stem cells (WJSCs). Oxidative Medicine and Cellular Longevity. 2019;2019.

38. Yoon D, Kim Y, Jung H, Paik S, Lee J. Importance of Sox2 in maintenance of cell proliferation and multipotency of mesenchymal stem cells in low-density culture. Cell proliferation. 2011;44(5):428-40.

39. Choi K-H, Lee D-K, Kim SW, Woo S-H, Kim D-Y, Lee C-K. Chemically defined media can maintain pig pluripotency network in vitro. Stem cell reports. 2019;13(1):221-34.

\section{Tables}

Table 1. The number of total cells and pluripotent marker positive cells

\begin{tabular}{|llllll|}
\hline Group & $\begin{array}{l}\text { No. blastocyst } \\
(\mathrm{n}=3)\end{array}$ & \multicolumn{4}{l}{ Cells in blastocysts } \\
\cline { 2 - 6 } & $\begin{array}{l}\text { Total cell } \\
\text { number }\end{array}$ & $\begin{array}{l}\text { sox2 } \\
\text { positive cells }\end{array}$ & $\begin{array}{l}\text { NANOG } \\
\text { positive cells }\end{array}$ & $\begin{array}{l}\text { sox17 } \\
\text { positive cells }\end{array}$ \\
\hline Cont. & 30 & $131.8 \pm 8.4^{\mathrm{a}}$ & $17.6 \pm 1.6^{\mathrm{a}}$ & $6.8 \pm 1.4^{\mathrm{a}}$ & $7.2 \pm 1.6^{\mathrm{a}}$ \\
\hline $\begin{array}{l}\text { PX458- } \\
\text { empty }\end{array}$ & 30 & $117 \pm 6.5^{\mathrm{a}}$ & $13.4 \pm 1.6^{\mathrm{a}}$ & $4.7 \pm 0.8^{\mathrm{a}}$ & $6.2 \pm 1.0^{\mathrm{a}}$ \\
\hline $\begin{array}{l}\text { PX458-Sox2 } \\
\text { gRNA }\end{array}$ & 30 & $29 \pm 2.5^{\mathrm{b}}$ & $1.6 \pm 0.6^{\mathrm{b}}$ & $0.8 \pm 0.4^{\mathrm{b}}$ & $0.3 \pm 0.2^{\mathrm{b}}$ \\
\hline
\end{tabular}

Table 2. Developmental rates of SOX2 overexpressed embryos

\begin{tabular}{|llll|}
\hline Group & No. embryos $(n=3)$ & No. cleaved (\%) & Blastocyst (\%) \\
\hline pCXLE-pSOX2 & 101 & $71(71.7 \pm 0.03)$ & $8(8.1 \pm 0.03)$ \\
1C stage injected & & & \\
\hline $\begin{array}{l}\text { CMV-GFP } \\
\text { 1C stage injected }\end{array}$ & 91 & $71(77.9 \pm 0.05)$ & $32(35.2 \pm 0.01)$ \\
\hline $\begin{array}{l}\text { Media } \\
\text { 1C stage injected }\end{array}$ & 90 & $68(75.6 \pm 0.03)$ & $26(28.9 \pm 2.94)$ \\
\hline
\end{tabular}

\section{Figures}



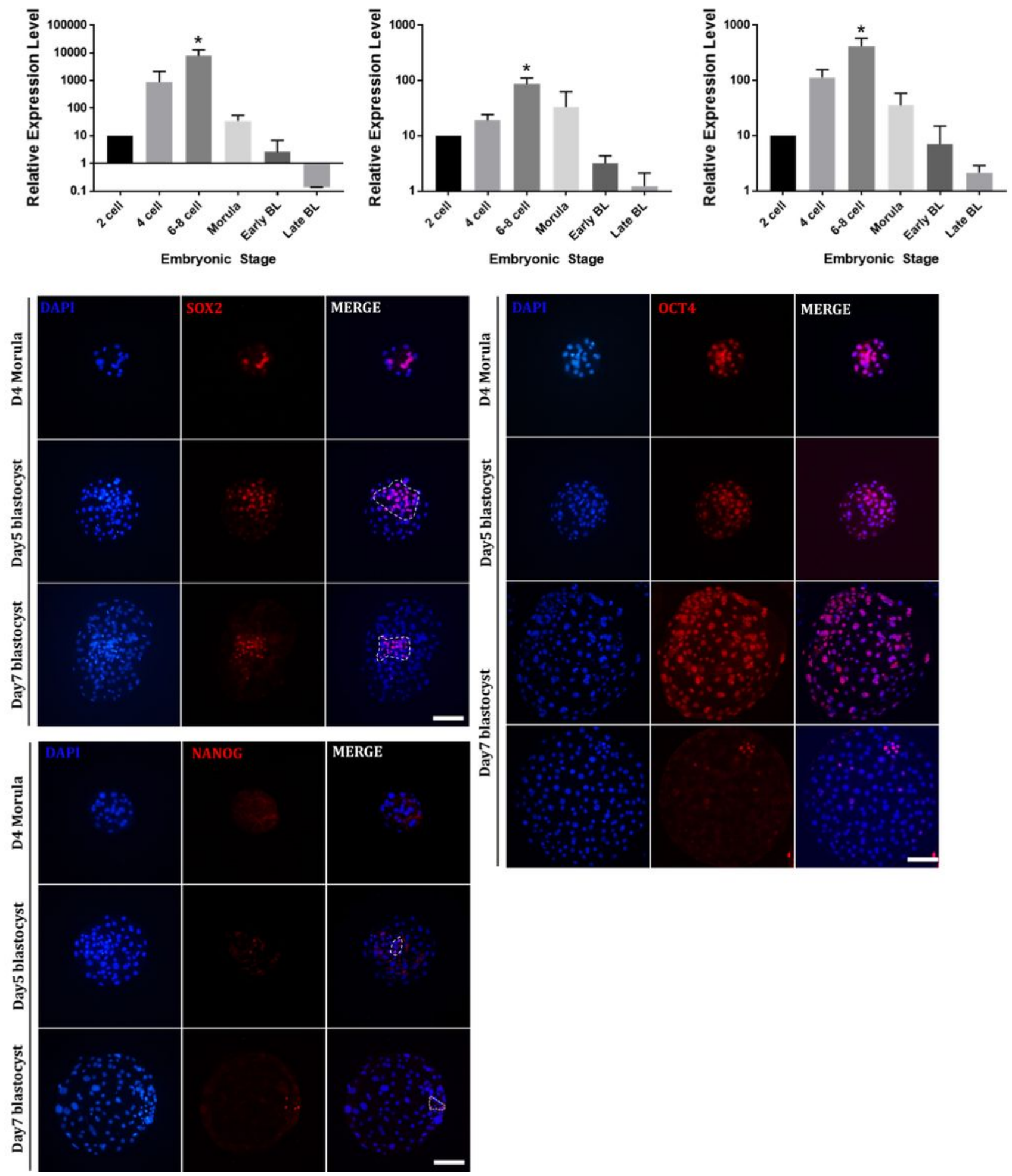

Figure 1

Core pluripotency factor expression pattern in preimplantation porcine embryos (A) PA embryos in 6 developmental stages ( 2 cells, 4 cells, 6-8 cells, Early Blastocyst, Late Blastocyst) were used for RNA extraction and CDNA synthesis. Data were normalized against the endogenous reference gene ACTB, and the data from each stage were relative to the 2-cell stage. We analyzed the relative expression levels of core pluripotency genes (SOX2, OCT4A, NANOG). Error bars represent the mean S.E.M., * indicates a 
significant difference between groups. (B) Expression and localization of core pluripotent genes in 3 developmental stages (Morula, Early Blastocyst, Late Blastocyst) of PA embryos. DNA was stained with DAPI, and SOX2, OCT4A, and NANOG were stained red. Size marker corresponds to $100 \mu \mathrm{m}$.

sox2

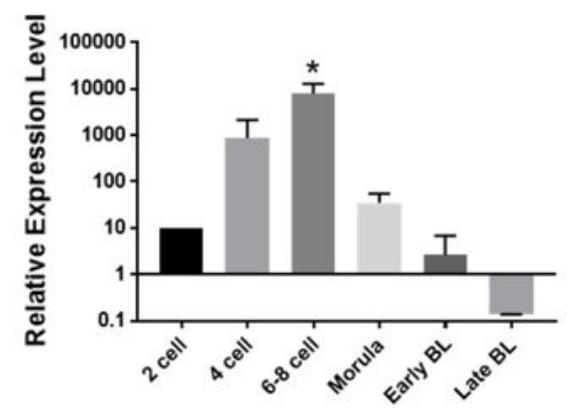

Embryonic Stage

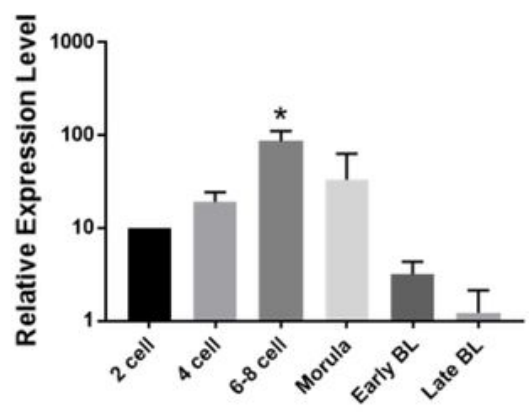

Embryonic Stage

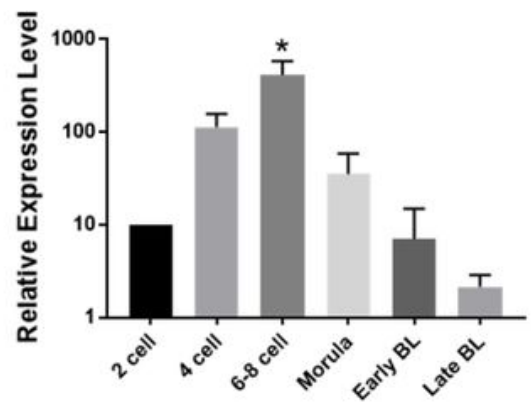

Embryonic Stage
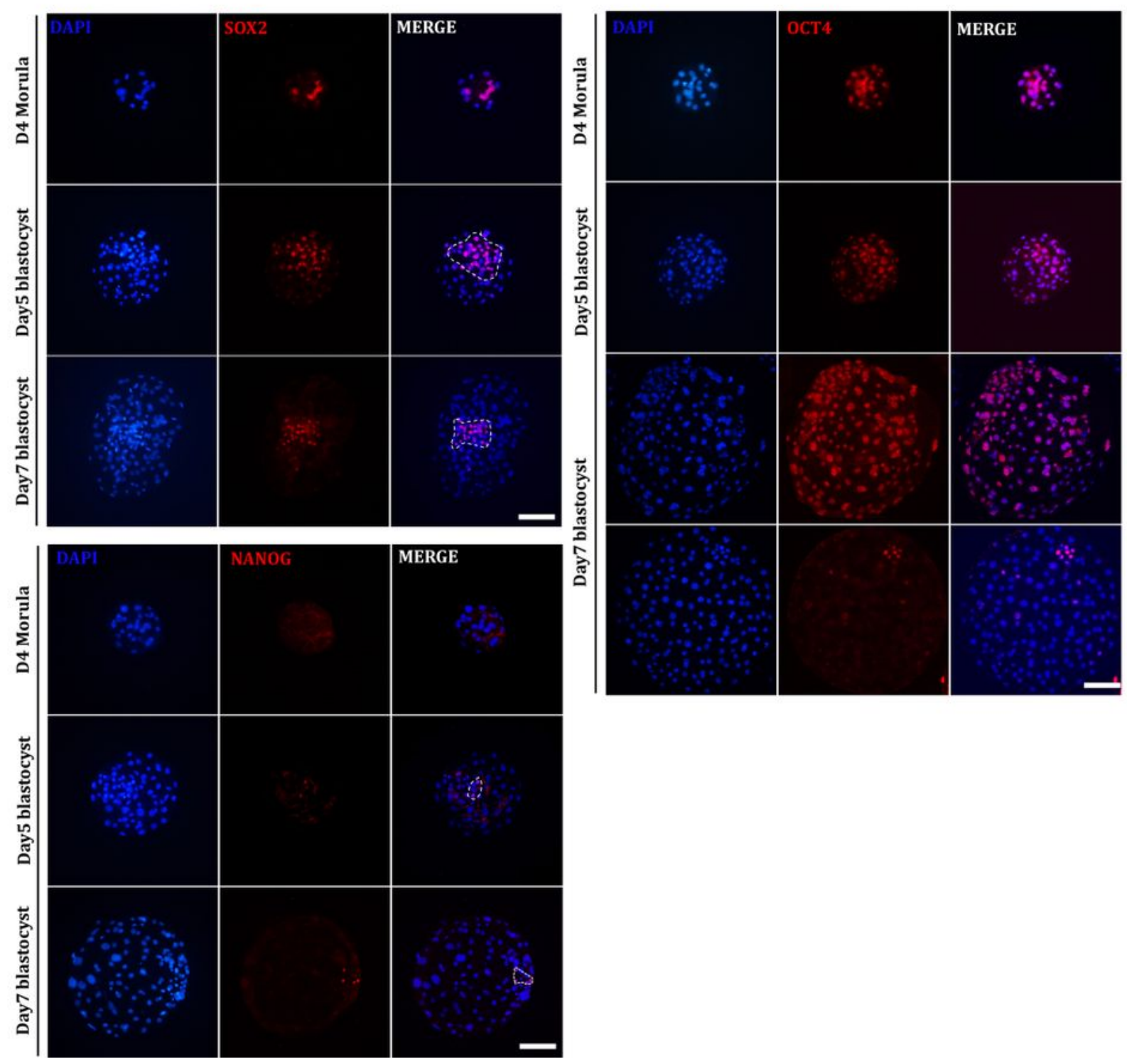

Figure 1

Core pluripotency factor expression pattern in preimplantation porcine embryos (A) PA embryos in 6 developmental stages ( 2 cells, 4 cells, 6-8 cells, Early Blastocyst, Late Blastocyst) were used for RNA 
extraction and CDNA synthesis. Data were normalized against the endogenous reference gene ACTB, and the data from each stage were relative to the 2-cell stage. We analyzed the relative expression levels of core pluripotency genes (SOX2, OCT4A, NANOG). Error bars represent the mean S.E.M., * indicates a significant difference between groups. (B) Expression and localization of core pluripotent genes in 3 developmental stages (Morula, Early Blastocyst, Late Blastocyst) of PA embryos. DNA was stained with DAPI, and SOX2, OCT4A, and NANOG were stained red. Size marker corresponds to $100 \mu \mathrm{m}$. A
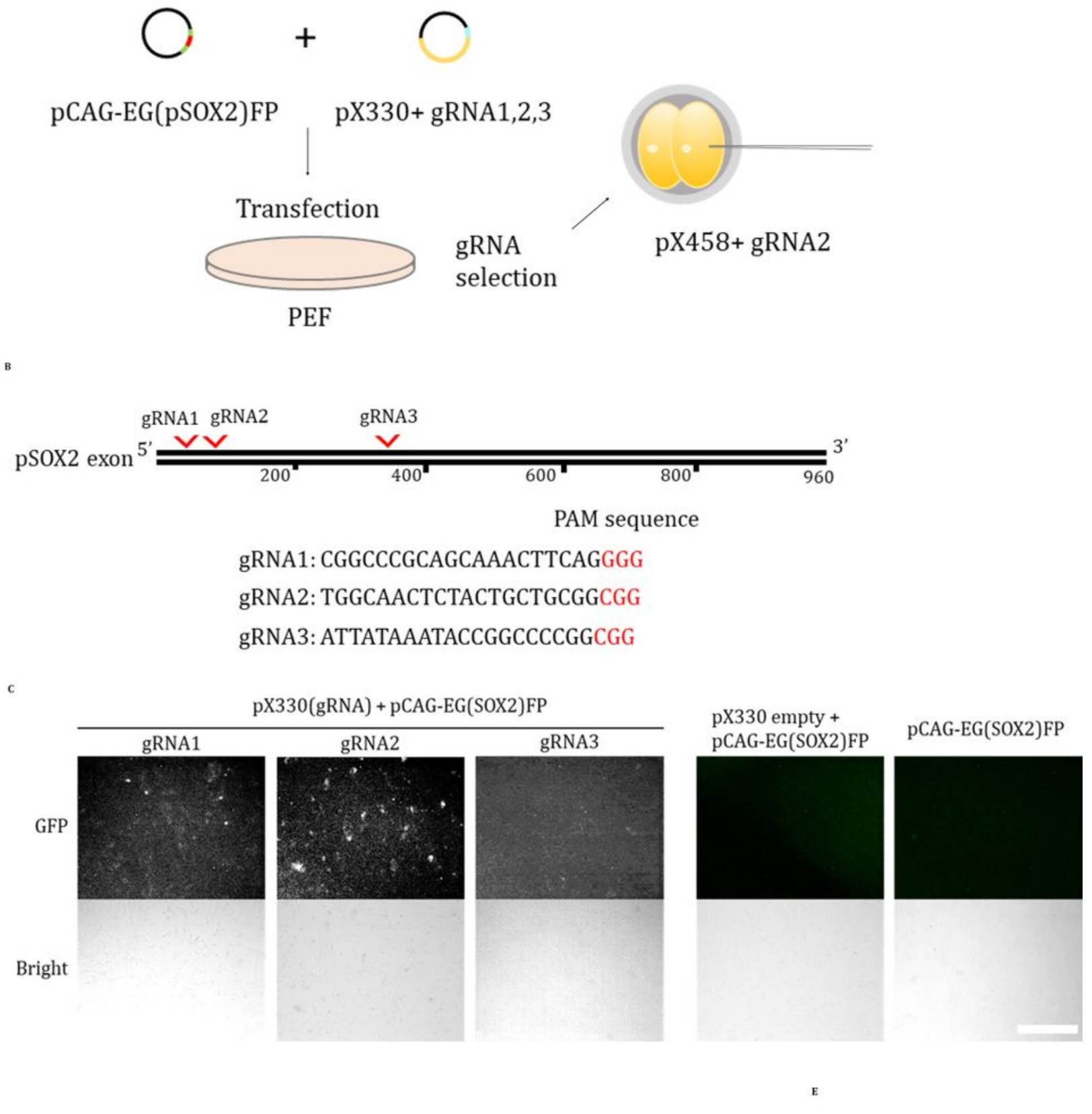
Reference: TGGCAACTCTACTGCTGCGGCGG \#1 1 bp deletion: TGGCAACTCTACTGC-GCGGCGG \#2 4 bp deletion: TGGCAACTCTAC - - --GCGGCGG \#3 1 bp deletion: TGGCAACTCTACTG-TGCGGCGG

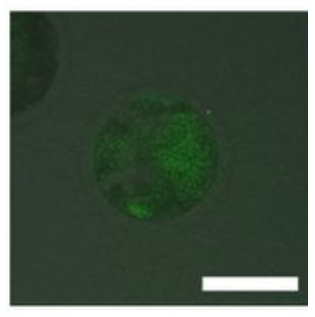


Experimental scheme and CRISPR gRNA validation (A) Experimental scheme of SOX2 targeting of porcine embryos. (B) Porcine SOX2 locus and gRNA targeting sites. PAM sequences are indicated in red font. (C) The cleavage efficiency of pX330, which contains gRNA 1 to 3 sequences, in the porcine SOX2 region of the PCAG-EGXXFP vector. (D) Deletion mutations in porcine embryonic fibroblasts transfected with pX330 (gRNA2). (E) Day 5 porcine blastocyst microinjected with Px458 (gRNA2) lipofectamine complex.
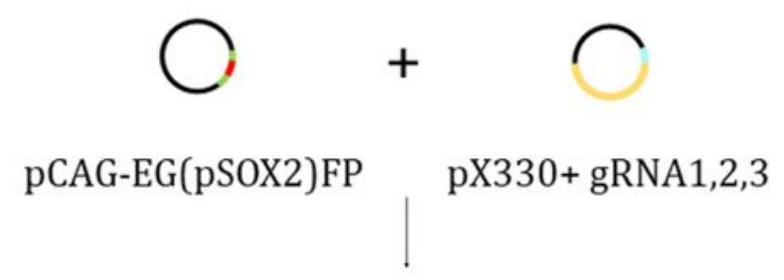

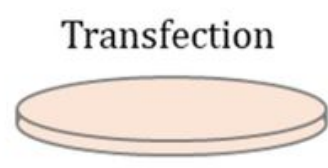

gRNA selection

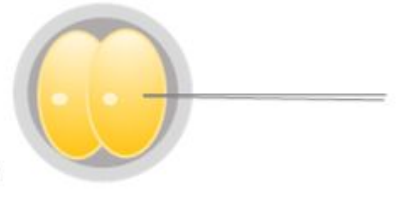

pX458+ gRNA2

PEF

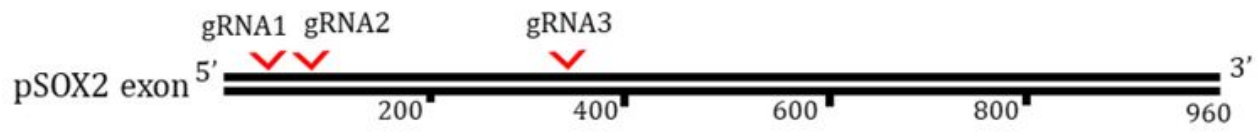

PAM sequence

gRNA1: CGGCCCGCAGCAAACTTCAGGGG gRNA2: TGGCAACTCTACTGCTGCGGCGG gRNA3: ATTATAAATACCGGCCCCGGCGG

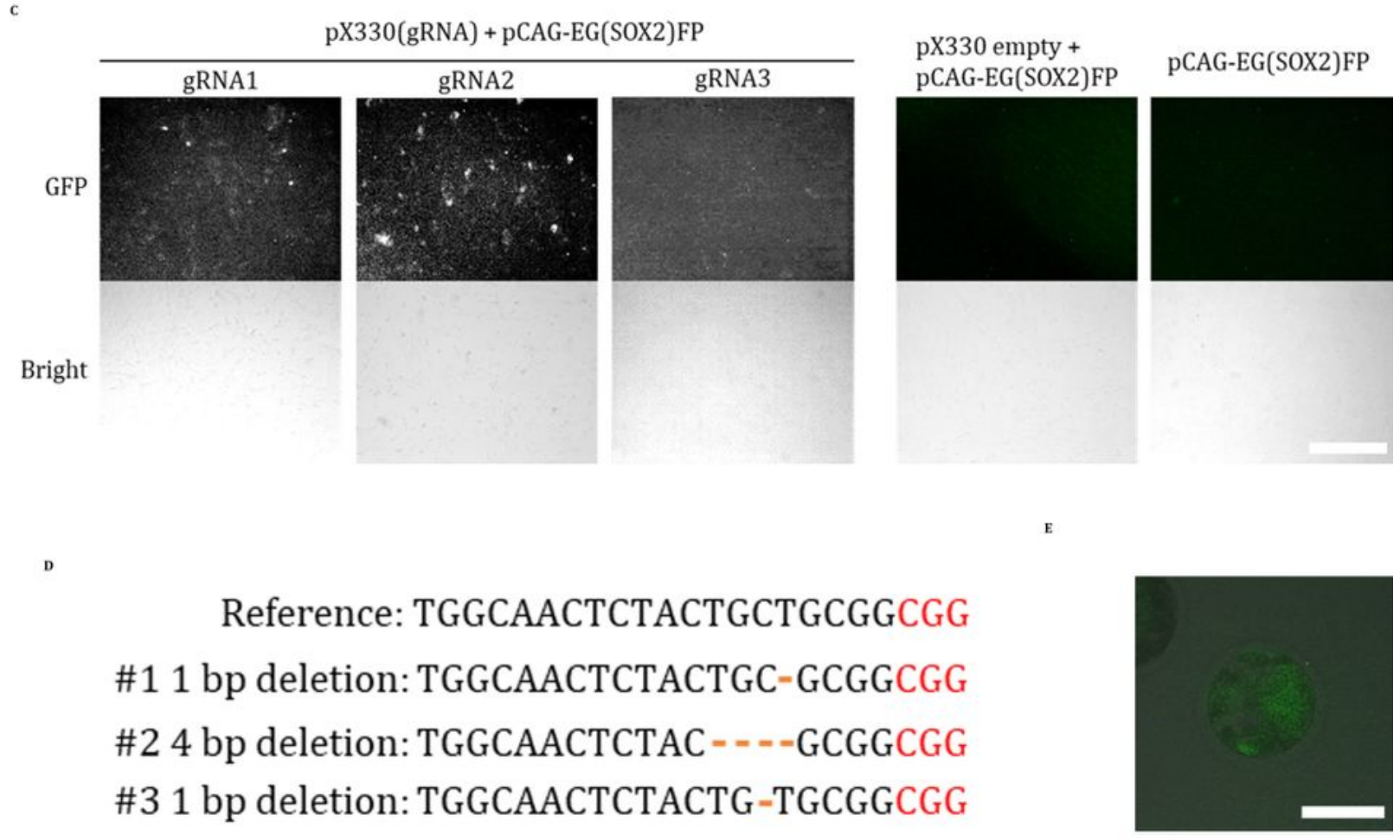


Experimental scheme and CRISPR gRNA validation (A) Experimental scheme of SOX2 targeting of porcine embryos. (B) Porcine SOX2 locus and gRNA targeting sites. PAM sequences are indicated in red font. (C) The cleavage efficiency of pX330, which contains gRNA 1 to 3 sequences, in the porcine SOX2 region of the pCAG-EGXXFP vector. (D) Deletion mutations in porcine embryonic fibroblasts transfected with pX330 (gRNA2). (E) Day 5 porcine blastocyst microinjected with Px458 (gRNA2) lipofectamine complex.

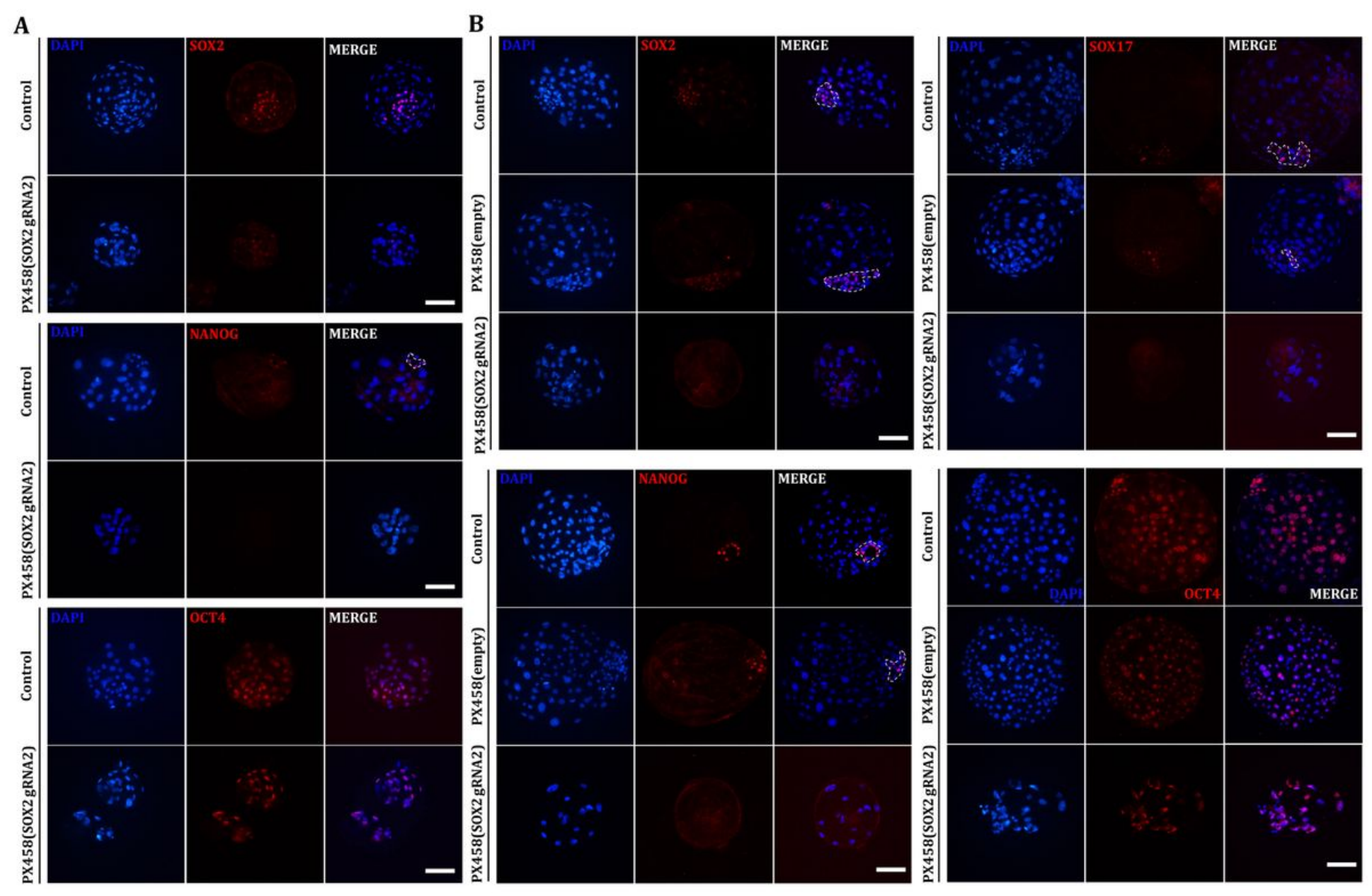

\section{Figure 3}

Targeting SOX2 prevents the expression of ICM-specific genes in porcine embryos (A) Immunofluorescence analysis of pluripotent genes (SOX2, NANOG, OCT4-red) and DAPI nuclear staining (blue) in uninjected and pX458 + gRNA-injected porcine early BL. The sample size of each group was $n=10$. (B) Immunofluorescence analysis of pluripotent genes (SOX2, NANOG, OCT4-red) and DAPI nuclear staining (blue) in uninjected, pX458-injected, pX458 + gRNA-injected porcine late BL. The sample size of each group was $n=10$. Size marker corresponds to $100 \mu \mathrm{m}$. 


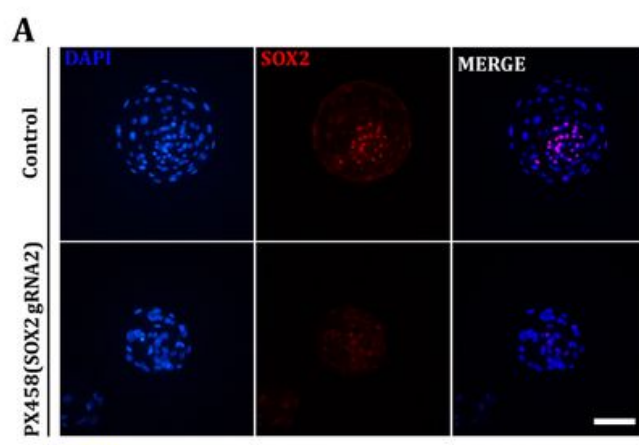

\section{B}
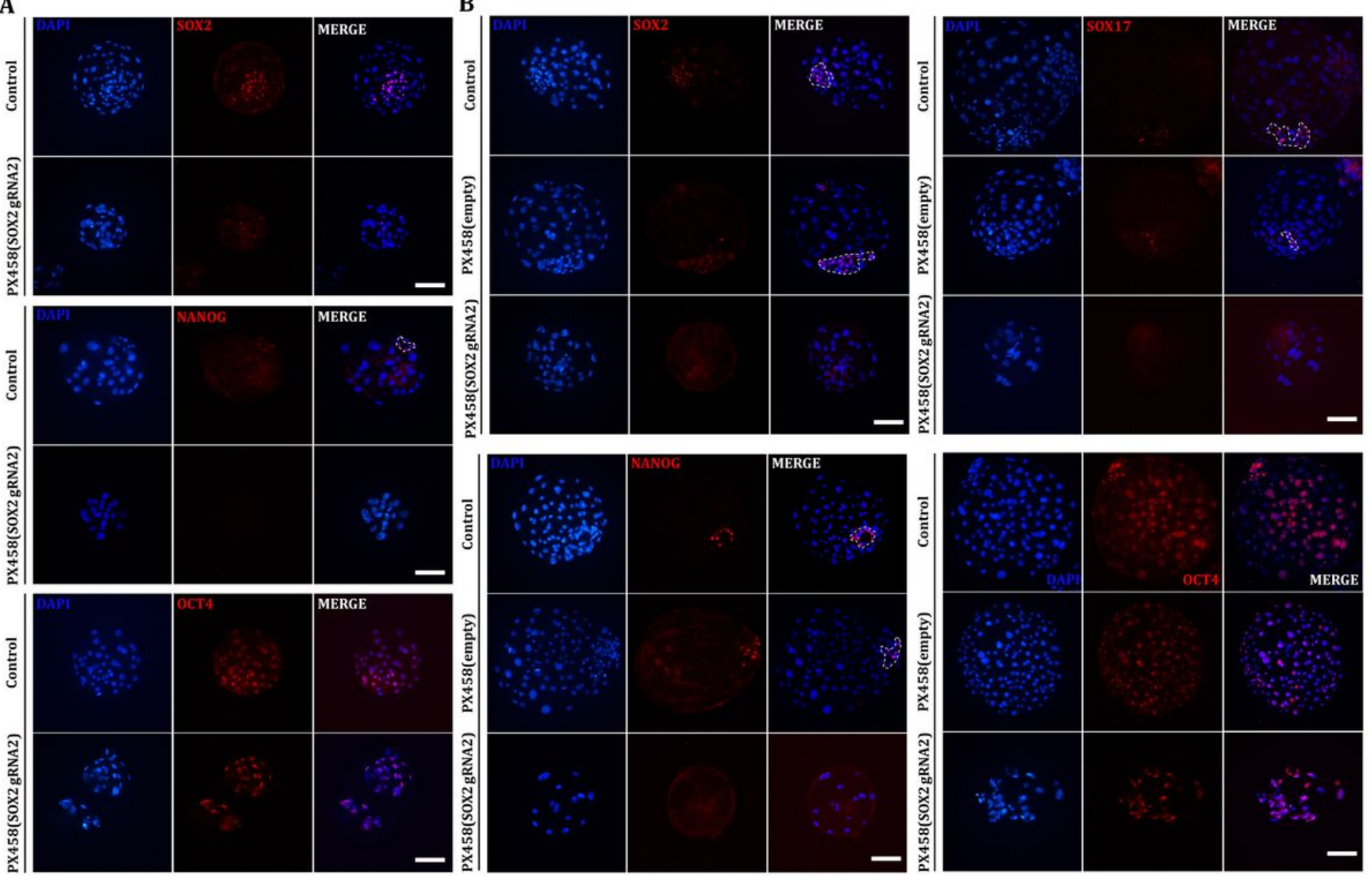

\section{Figure 3}

Targeting SOX2 prevents the expression of ICM-specific genes in porcine embryos (A) Immunofluorescence analysis of pluripotent genes (SOX2, NANOG, OCT4-red) and DAPI nuclear staining (blue) in uninjected and pX458 + gRNA-injected porcine early BL. The sample size of each group was $n=10$. (B) Immunofluorescence analysis of pluripotent genes (SOX2, NANOG, OCT4-red) and DAPI nuclear staining (blue) in uninjected, pX458-injected, pX458 + gRNA-injected porcine late BL. The sample size of each group was $n=10$. Size marker corresponds to $100 \mu \mathrm{m}$. 
sox2

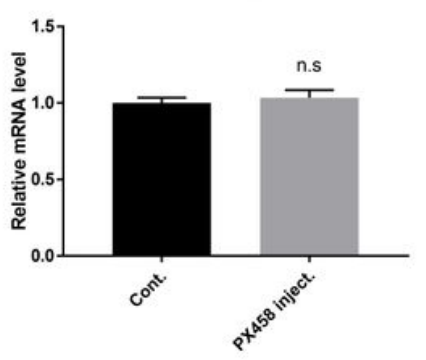

sox17

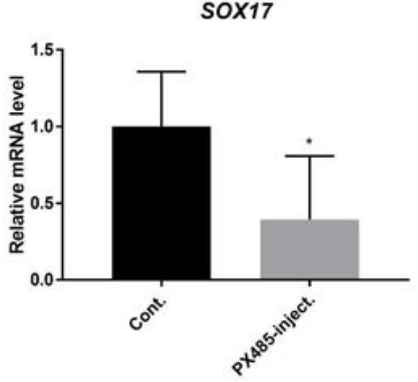

sox 2

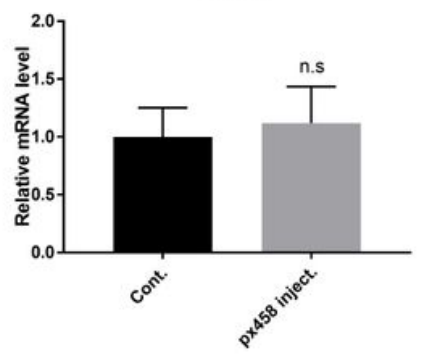

sox17

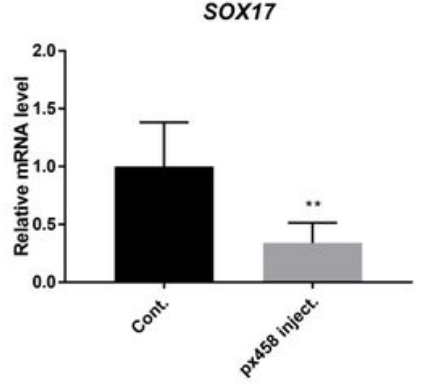

OCT4A

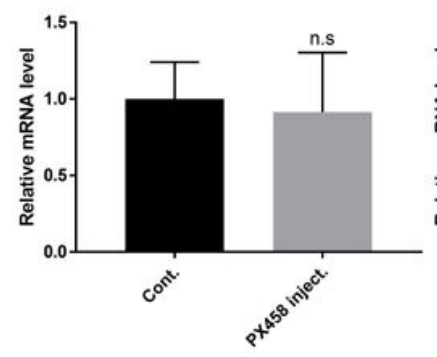

SMAD7

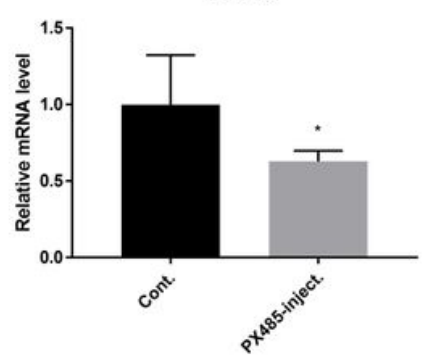

OCT4A
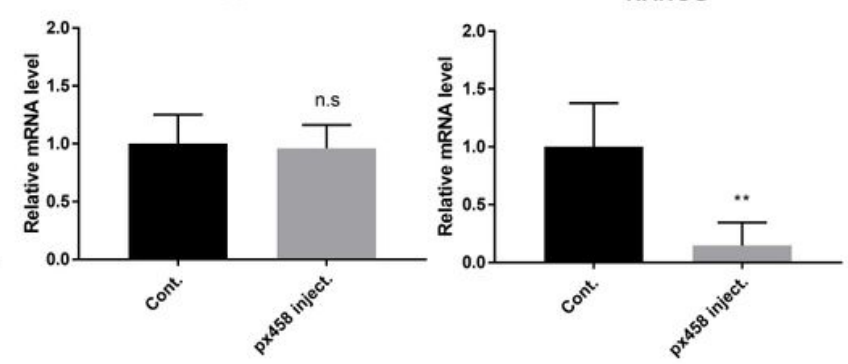

SMAD7

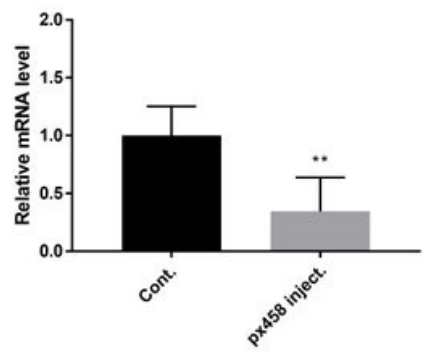

NANOG

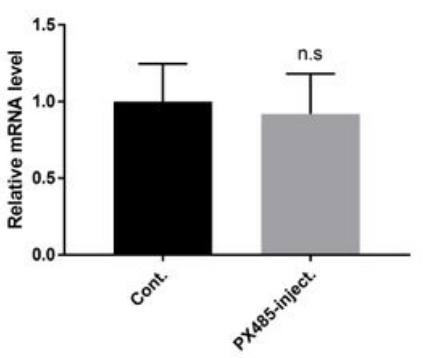

$$
\frac{1}{2}
$$
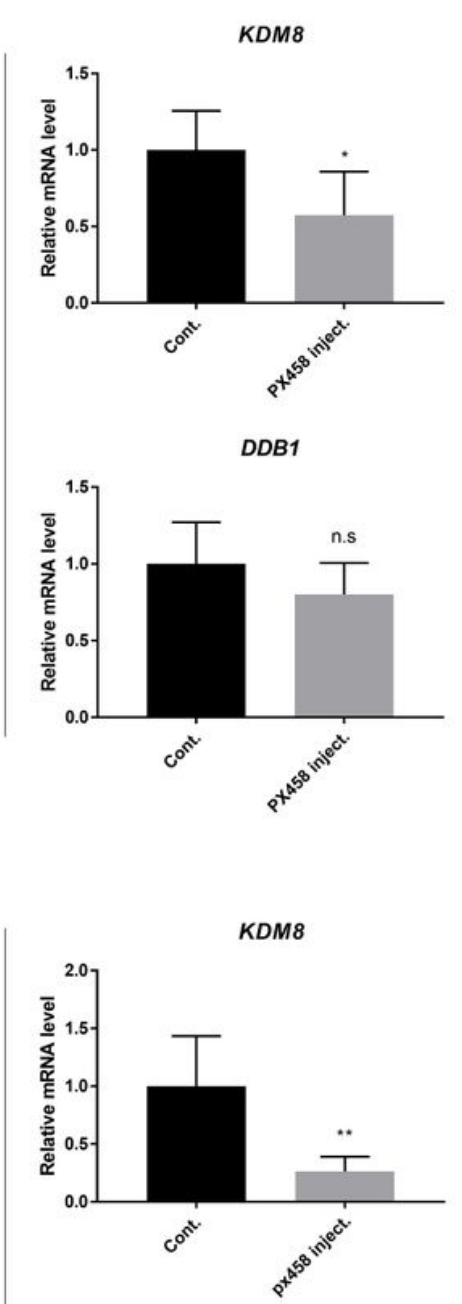

DDB1

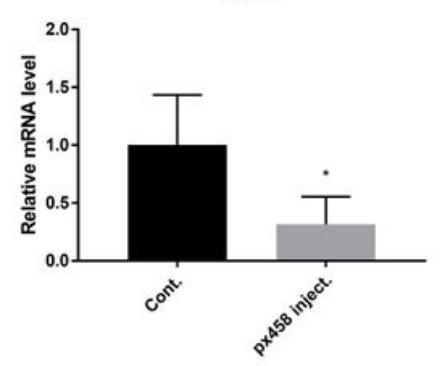

\section{Figure 4}

Gene expression patterns of proliferation and pluripotency genes in SOX2-targeted porcine embryos (A) Transcription levels of pluripotency-related genes in uninjected and SOX2-targeted day 5 blastocysts. (B) Transcription levels of proliferation-related genes in uninjected and SOX2-targeted day 5 blastocysts. (C) Transcription levels of pluripotency-related genes in uninjected and SOX2-targeted day 7 blastocysts. (D) Transcription levels of proliferation-related genes in uninjected and SOX2-targeted day 7 blastocysts. * Corresponds to significant differences ( $\left.{ }^{*}: p<0.05, * *: p<0.01\right)$. 
sox2

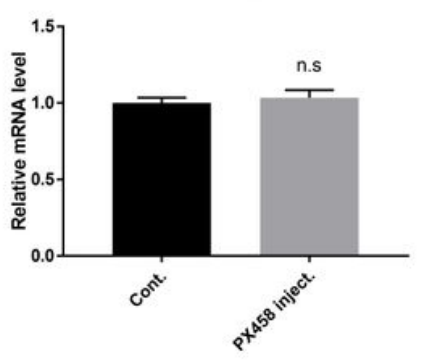

sox17

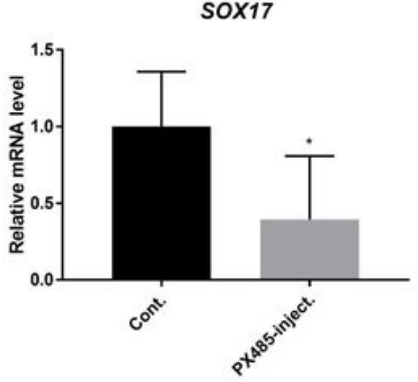

sox 2

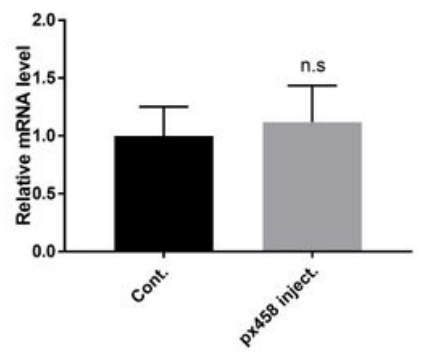

sox17

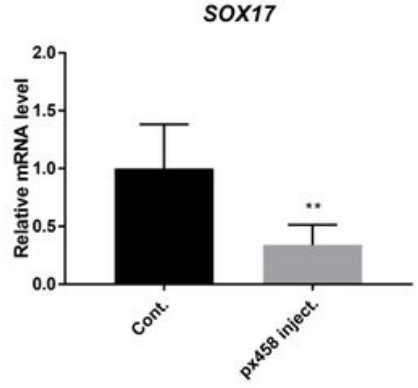

OCT4A

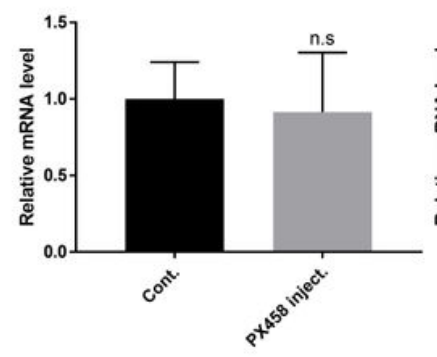

SMAD7

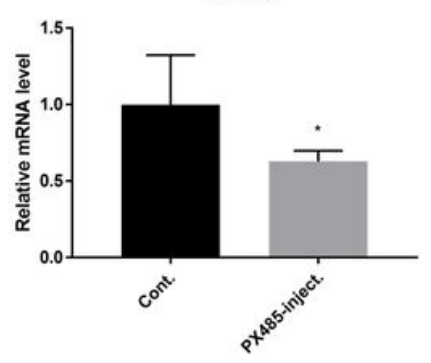

OCT4A
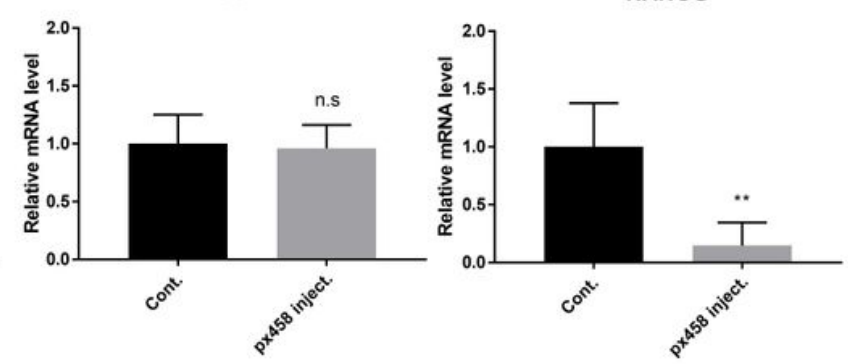

SMAD7

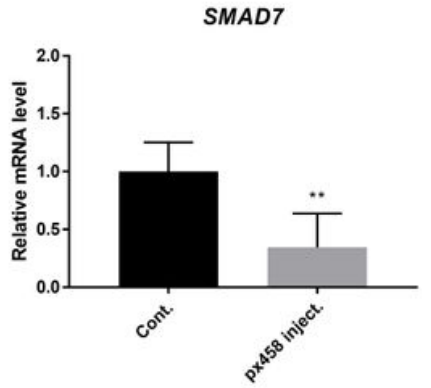

NANOG

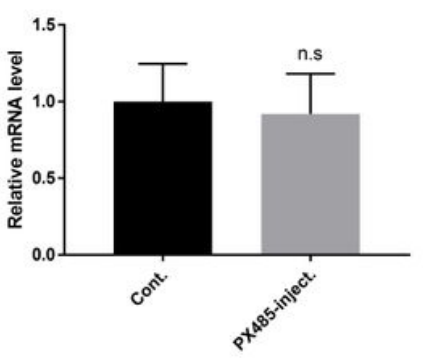

$$
\frac{1}{2}
$$
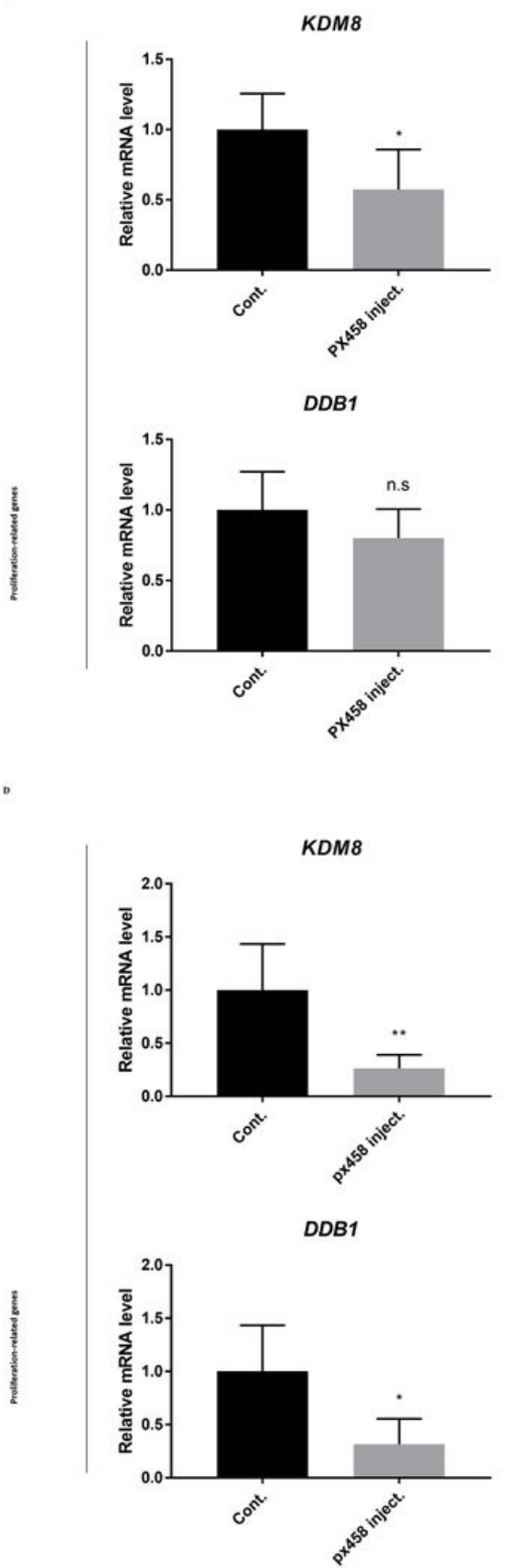

\section{Figure 4}

Gene expression patterns of proliferation and pluripotency genes in SOX2-targeted porcine embryos (A) Transcription levels of pluripotency-related genes in uninjected and SOX2-targeted day 5 blastocysts. (B) Transcription levels of proliferation-related genes in uninjected and SOX2-targeted day 5 blastocysts. (C) Transcription levels of pluripotency-related genes in uninjected and SOX2-targeted day 7 blastocysts. (D) Transcription levels of proliferation-related genes in uninjected and SOX2-targeted day 7 blastocysts. * Corresponds to significant differences ( $*: p<0.05, * \star: p<0.01)$. 

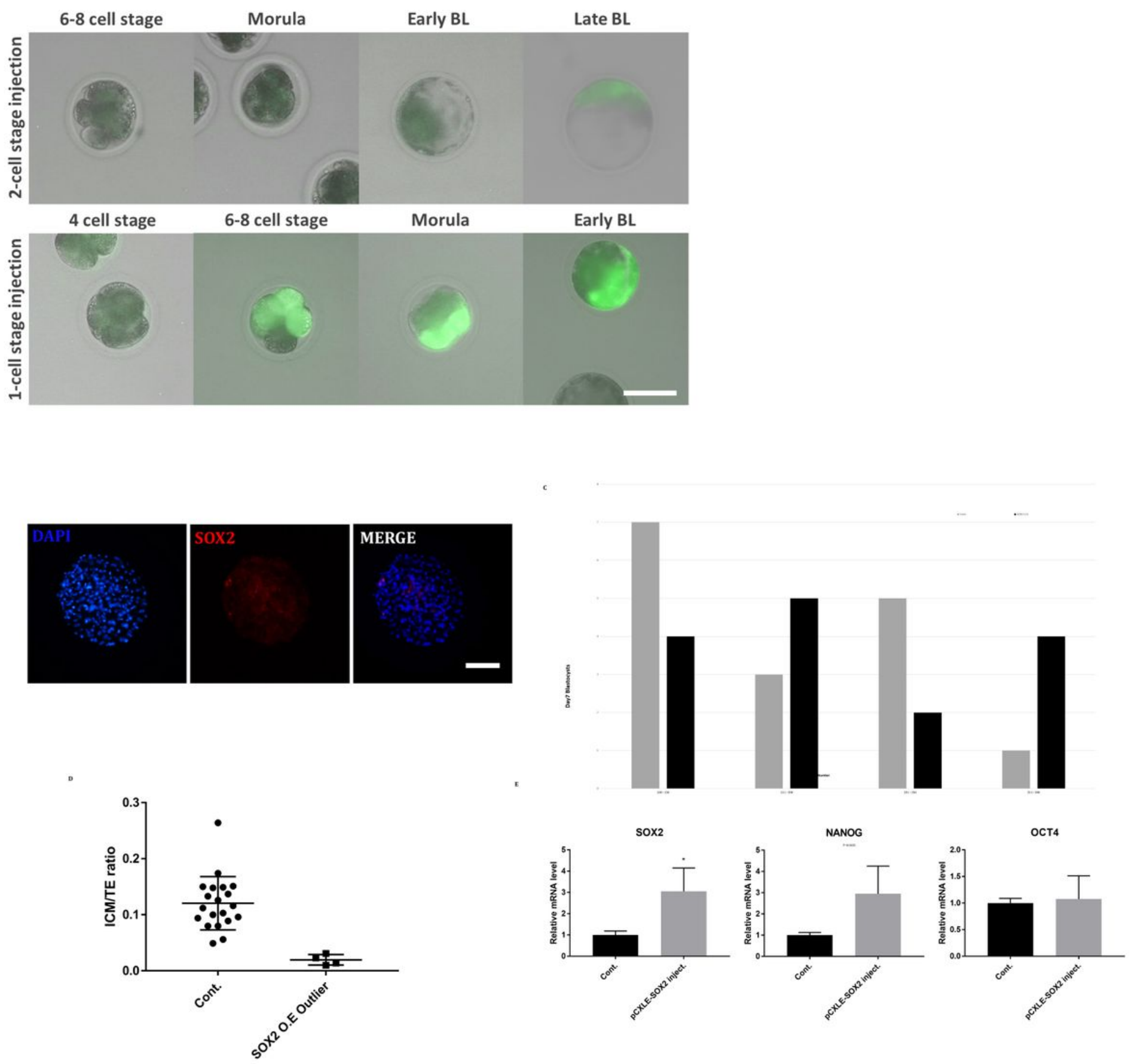

\section{Figure 5}

Analysis of SOX2-overexpressing porcine blastocysts. (A) GFP expression during the development of embryos injected with pCXLE-pSOX2 at the 1-cell stage and 2-cell stage. Size marker corresponds to 100 $\mu \mathrm{m}$. (B) Immunofluorescence analysis for SOX2 (red) and DAPI nuclear staining in SOX2-overexpressing day 7 blastocysts. Size marker corresponds to $100 \mu \mathrm{m}$. (C) Number of blastocysts per total cell number in control and SOX2-overexpressing day 7 blastocysts. (D) Cell allocation to the ICM and TE in control and outliers with high total cell numbers among SOX2-overexpressing embryos. (E) Transcription levels of pluripotency-related genes in uninjected and SOX2-overexpressing day 7 blastocysts. 

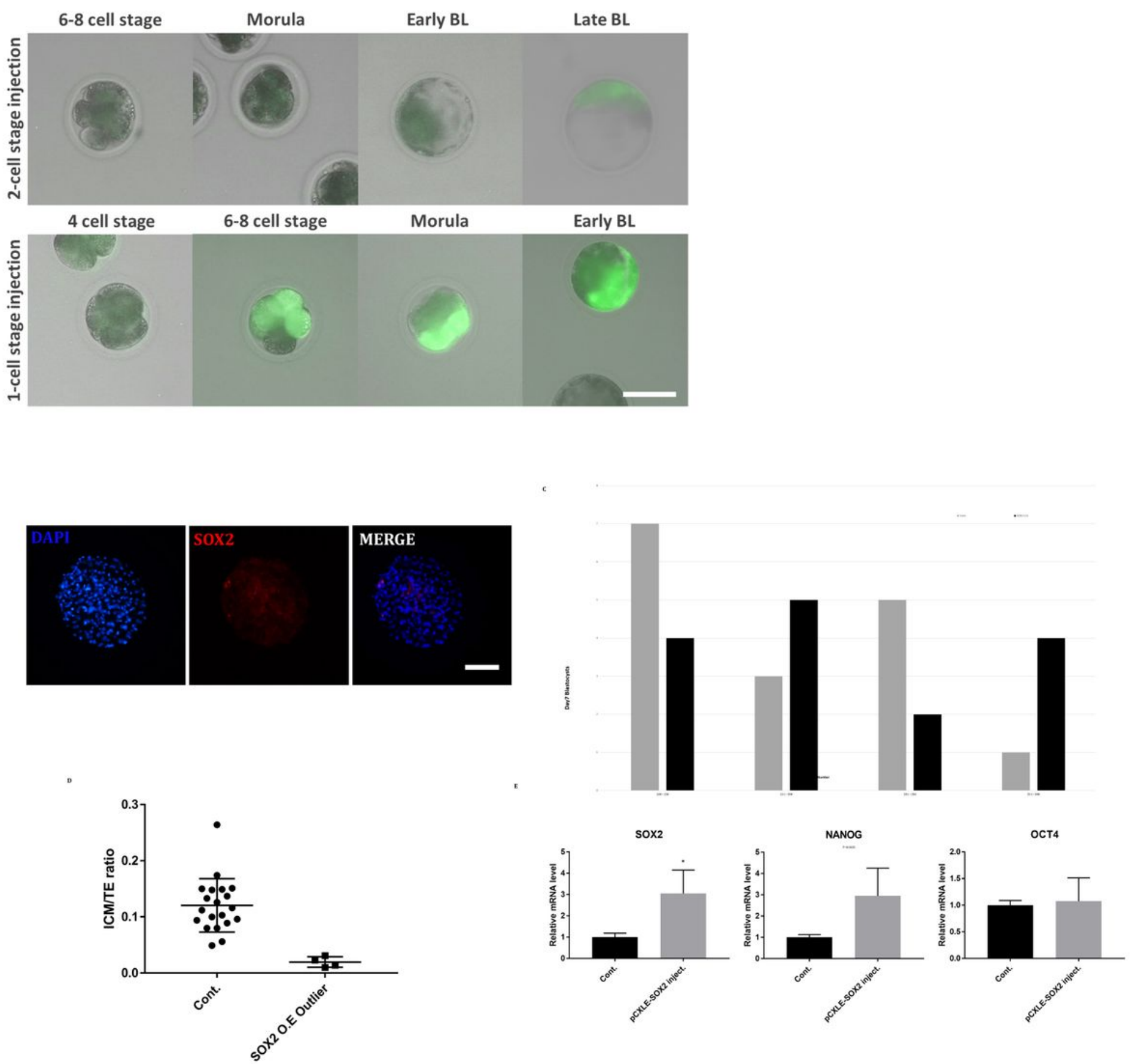

\section{Figure 5}

Analysis of SOX2-overexpressing porcine blastocysts. (A) GFP expression during the development of embryos injected with pCXLE-pSOX2 at the 1-cell stage and 2-cell stage. Size marker corresponds to 100 $\mu \mathrm{m}$. (B) Immunofluorescence analysis for SOX2 (red) and DAPI nuclear staining in SOX2-overexpressing day 7 blastocysts. Size marker corresponds to $100 \mu \mathrm{m}$. (C) Number of blastocysts per total cell number in control and SOX2-overexpressing day 7 blastocysts. (D) Cell allocation to the ICM and TE in control and outliers with high total cell numbers among SOX2-overexpressing embryos. (E) Transcription levels of pluripotency-related genes in uninjected and SOX2-overexpressing day 7 blastocysts. 


\section{Supplementary Files}

This is a list of supplementary files associated with this preprint. Click to download.

- supplementrytable1and2.docx

- supplementrytable1and2.docx 